ment, are often expected to carry out lumbar puncture with only scant knowledge of the procedure.

In spite of the fashionable trend away from the use of spinal analgesia in anaesthetic practice, it is still very widely used throughout the world.

Surgeons who like to administer their own spinal anaesthetics might refer to this book with advantage.

However, anaesthetists, especially those reading for higher diplomas, will probably wish to look elsewhere for a more comprehensive account of the clinical side of spinal analgesia, especially with regard to the varying techniques, and to diagnostic and therapeutic uses of the art.

$$
\text { C.C.C. }
$$

\section{BLOOD PRESSURE SOUNDS AND THEIR MEANINGS}

By John Erskine Malcolm, B.Sc., M.B., Ch.B., F.R.C.S. Pp. vii +93 , with 45 illustrations. London: William Heinemann Ltd. 1957. I2s. $6 \mathrm{~d}$.

Those of us who, in our innocence, imagine that the sounds arising from the antecubital fossa during measurement of the arterial blood pressure are a simple matter of blood rushing through a constricted segment of artery, are rudely shaken by this short book. The Korotkov sounds are ingeniously demonstrated to be a function of a curve expressing the pressure-volume relationship of the artery under the cuff.

The business of the book is to present the evidence for the author's theory of systemic arterial resonance. Briefly stated, the arteries are postulated as being in a state of resonance, due to impulses from the heart and their reflections. Systams of stationary, non-progressive waves of fixed length and position develop in the arterial system.

While this book is essentially one for the specialist in circulatory dynamics, the concept put forward and its implications in terms of deforming and injurious forces on the arterial wall is of sufficient importance to merit consideration from all those interested in arterial disease generally and in its mechanical aspects in particular.

H.K.

\section{SURGERY OF THE ANUS, ANAL CANAL AND RECTUM}

By E. S. R. Hughes, M.D., M.S., F.R.C.S. F.R.A.C.S. Pp. xi +304 , with 276 illustrations. Edinburgh: E. \& S. Livingstone Ltd. 1957. £2 ros.

It is a great pleasure to read a new British book on proctology. Mr. Hughes presents his subject in an admirably clear and succinct form with carefully chosen, clear illustrations. No space is wasted and no excess of wordage or picture allowed to confuse the various issues. While largely a commentary of Mr. Hughes' own work with its flavour of St. Mark's, the contents are not onesided and a suitable selection of the most important references is given. The book covers the whole field of proctology and when this relatively narrow field impinges upon and continues into related areas, these points of contact and associated areas are surveyed.

The ending of the book with an historical appendix, a most happy and enlightening chapter, completes the perspective of Mr. Hughes' thoroughly excellent presentation which is most strongly recommended to all to whom proctology is of moment.

A.E.C.

\section{DISEASES AND DISORDERS OF THE COLON}

By ANthony Bassler, M.D., F.A.C.P., F.A.C.G., LL.D. Pp. ix +217 , with 79 illustrations. Oxford: Blackwell Scientific Publications. 1957. 5 Is.

The author of this book is a physician and he attempts to cover both the medical and surgical affections of the colon. The medical sections contain much useful information, but they are spoilt by careless writing and bad arrangement. There are, for instance, two separate chapters on parasitic disorders: one of these includes an account of the intestinal effects of hyperthyroidism and of parathyroid and adrenal deficiency; the other contradicts several statements made in the first. The surgical portions are frankly misleading.

H.L.B.

\section{PULMONARY COMPLICATIONS OF ABDOMINAL SURGERY}

By A. R. Anscombe, M.S., F.R.C.S. Pp. $x+121$, illustrated. London: Lloyd-Luke Ltd. I 957. £I.

The author of this monograph should feel well satisfied with his work. Much that has hitherto been the result of clinical impression or demonstrable only incompletely by experiment is explained. While the techniques used may not have everyday applications they are sufficiently practicable to be brought into use easily for investigation of respiratory problems associated with surgical work.

While many of the facts elicited are of a confirmatory nature, the demonstration, for example, that the transthoracic approach to the gastrooesophageal area produces less post-operative respiratory disability than the transabdominal route may raise not a few eyebrows; and this is by no means the only, perhaps unexpected, fact demonstrated.

The publishers have produced an eminently readable volume which should be read by all who undertake the care of surgical patients.

A.E.C. 